\title{
The endothelium: its role in scleroderma
}

\author{
Jeremy D Pearson
}

Vascular dysfunction, in particular microvascular pathology perhaps most closely associated with arterioles, is a cardinal sign in the development of systemic sclerosis (scleroderma). Altered vascular reactivity and structure provide only one element in a spectrum of pathological alterations associated with the clinical development of the disease. Nonetheless, the almost invariable pre-existence of Raynaud's phenomenon before the development of scleroderma makes it clear that altered blood vessel responsiveness is an early event in the progression of the disease. These considerations led Campbell and LeRoy to propose as early as 1975 that the primary cause of scleroderma involved endothelial cell damage and dysfunction. ${ }^{1}$

Since then, mainly as a consequence of the ability to isolate and culture endothelial cells routinely (first described in 1973), our understanding of endothelial cell biology has advanced rapidly. ${ }^{2}$ Previously thought of by many as at best a selective permeability barrier between blood and tissues, it is now apparent that endothelium regulates actively many aspects of vascular homeostasis. It can be regarded realistically as a cell type that responds to molecular signals generated locally or distantly and hence controls metabolic and cellular events in the tissues of the body, in a manner which is at least as all-pervading as neuronal regulation.

It still remains hypothetical that disturbance of endothelial cell function is a necessary or primary event for the development of scleroderma, but there is increasing evidence that the involvement of endothelial cells is an important element in the pathogenesis of the disease. This review outlines first our current understanding of several major aspects of endothelial cell biology, derangements of which might be expected to contribute to vascular pathology. In the light of this the next section summarises the particular features of scleroderma that may indicate endothelial pathology and suggests what the molecular mechanism of damage may be

\section{Endothelial cell biology}

CONTROL OF VASCULAR TONE

In 1980 Furchgott and Zawadzki ${ }^{3}$ first showed that relaxation of isolated vascular smooth muscle strips from a variety of vessels in response to several dilator agonists is dependent on the presence of intact endothelial cells, and is due to the production of a highly labile soluble mediator from endothelium, termed endothelium derived relaxing factor. ${ }^{4}$ Subsequently, a series of definitive studies from Moncada,
Palmer, and colleagues led to the identification of this relaxing factor as nitric oxide and to the demonstration that it was synthesised by endothelial cells from L-arginine. ${ }^{5} 6$

The half life of nitric oxide in biological systems is lengthened in the presence of superoxide dismutase because the superoxide radical anion rapidly destroys nitric oxide. ${ }^{7}$ Agents such as methylene blue or haemoglobin block the action of nitric oxide; the former by inhibiting its target enzyme (soluble guanylate cyclase) in smooth muscle cells ${ }^{8}$; and the latter by itself binding nitric oxide. ${ }^{9}$ More recently, several analogues of arginine-for example, $L$ $N$-monomethylarginine-have been shown to inhibit nitric oxide formation. ${ }^{10}$ Use of these various inhibitors has shown that both venous and arterial smooth muscle respond to endothelium derived relaxing factor and, more recently, that agonist induced, endothelium dependent vasodilatation, and thus control of blood flow and pressure, also occurs in microvascular beds. ${ }^{1-13}$ In addition, nitric oxide release can be detected continuously in isolated perfused organs, suggesting basal synthesis in endothelium, ${ }^{14}$ and importantly, this has been confirmed in vivo by showing that inhibition of nitric oxide synthesis by infusion of arginine analogues significantly raises systemic and regional blood pressure. ${ }^{15} 16$ Endothelial nitric oxide synthesis may therefore have a physiological role in the local control of blood flow, its release perhaps being regulated by shear sensitive or stretch sensitive receptors on the endothelium. ${ }^{17-19}$ More provocatively, Griffith and Edwards have argued that production of endothelium derived relaxing factor plays a necessary part in the efficient development and maintenance of the in vivo anatomy of microvascular beds. ${ }^{20}$

In the past three years it has been shown that endothelial cells also synthesise and secrete a highly potent vasoconstrictor peptide, endothelin. ${ }^{21}{ }^{22}$ The effects of endothelin on smooth muscle suggest that it acts as a functional antagonist to endothelium derived relaxing factor and that disturbances of its release or action might contribute to pathological vasoconstriction or spasm. There is as yet no clear understanding of the regulation of endothelin synthesis and release, or whether it is involved in physiological or pathological control of vascular tone in vivo.

CONTROL OF VASCULAR PERMEABILITY

Endothelial cells normally provide a selective permeability barrier to the passage of plasma constituents from the lumen to tissue spaces. By 
maintaining a pressure gradient across the vessel wall they contribute to the regulation of solute flux according to the balance of local oncotic and hydrostatic forces. In addition, macromolecules are effectively excluded to varying degrees, according to size and, perhaps, charge. ${ }^{2324}$ The existence of this barrier is more obviously recognised when it is disturbednotably, during the acute inflammatory response when greatly increased permeability to both solutes and macromolecules leads to oedema formation. This process, which primarily affects the venular side of microvascular beds, has long been known to occur in response to the release of soluble mediators, such as histamine and bradykinin (after local activation of mast cells or the coagulation cascade respectively). ${ }^{25}$ These mediators act directly on endothelial cell receptors to cause intercellular junctional changes by mechanisms that are still poorly understood. Williams and colleagues ${ }^{26}$ showed that the extent of oedema formation, particularly in the skin, is substantially potentiated in the concomitant presence of vasodilators - for example, prostanoids (see next subsection), which act upstream to dilate arterioles and hence increase blood flow and hydrostatic pressure. The same group has also investigated extensively the ability of a variety of neutrophil chemotactic agents to enhance oedema formation, and has shown that these agonists do so by causing the margination and emigration of neutrophils in postcapillary venules-that is, protein leakage is dependent, again in a manner not well understood, on neutrophil emigration. ${ }^{27}$ Increased permeability also occurs, when neutrophil binding to endothelium is induced by alterations in endothelial surface leucocyte adhesion molecules, or when intravascular or perivascular neutrophil activation leads to overt damage to endothelium ${ }^{28}$ (and see below).

\section{CONTROL OF HAEMOSTASIS AND THROMBOSIS}

Endothelium is normally antithrombotic and anticoagulant. This is due in part to mechanisms at the cell surface, including the expression of heparin-like proteoglycans and of thrombomodulin, which avidly binds thrombin and renders it anticoagulant by altering its proteolytic specificity so that it activates protein $C$ (which in turn inactivates coagulation factors $\mathrm{V}$ and VIII) rather than cleaving fibrinogen. ${ }^{29}$

In addition, local control of fibrinolysis is due to the triggered secretion of tissue plasminogen activator from endothelium in response to several agonists, such as thrombin or vasopres$\sin ^{30}$ Endothelium also produces the circulating physiological inhibitor of tissue plasminogen activator, though the details of how its secretion is regulated are not well understood..$^{31}$

The highly multimerised glycoprotein von Willebrand factor, which in the circulation acts as a carrier for coagulation factor VIII, is constitutively secreted by endothelial cells. In addition, von Willebrand factor is a cofactor for platelet adhesion to subendothelium, and its release from granular stores in endothelial cells is triggered by exposure to agonists similar to those that induce secretion of tissue plasminogen activator. ${ }^{32}$ Thus thrombin, for example, which initially stimulates platelet aggregation and coagulation to produce a haemostatic plug at a site of vessel damage, also induces endothelial cell responses designed to localise and limit thrombus formation.

A further way in which this is achieved is due to the receptor mediated stimulation of prostacyclin release from endothelial cells in response to agonists, including thrombin, and ATP and ADP released from aggregating platelets. ${ }^{33}$ Prostacyclin is a potent inhibitor of platelet aggregation, and in several vascular beds is also a potent dilator. Because it is released transiently in response to a range of agonists, of which many also induce release of endothelium derived relaxing factor, prostacyclin can also contribute to endothelium dependent vasodilatation. Conversely, nitric oxide, which can be released for longer periods, acts synergistically with prostacyclin to inhibit platelet aggregation, and (unlike prostacyclin) is an effective inhibitor of platelet adhesion. ${ }^{34}$

\section{INTERACTIONS WITH LEUCOCYTES}

Under physiological conditions endothelial cell interactions with leucocytes are transient and limited to specific vascular sites. Thus freely circulating neutrophils are in dynamic equilibrium with a marginated pool, primarily located in postcapillary venules, though also in capillaries in the pulmonary circulation, ${ }^{28} 35$ of cells that are temporarily attached to or moving on the surface of endothelium. Recirculating lymphocytes, in contrast, are efficiently extracted from the circulation in specific 'high' endothelial venules in lymphoid tissue, where lymphocytes bearing site selective homing receptors recognise complementary endothelial ligands ('addressins') and emigrate to reach areas where cell interactions involving antigen presentation can occur to generate the immune response. ${ }^{36}$ Similar 'high' endothelial venules develop at the sites of lymphocyte traffic in chronic inflammatory reactions, suggesting that lymphokines-for example, interferon $\gamma$ (see below), are involved in the development and maintenance of these phenotypically altered endothelial cells.

After early in vitro studies seeking to understand the modulation of leucocyte adhesion to endothelial cells ${ }^{3738}$ it was discovered that exposure of endothelial cells to specific acute inflammatory cytokines, or to supernatants containing lymphokines from leucocyte cultures, caused increased leucocyte adhesion. ${ }^{39-41}$ Subsequently, there has been a proliferation of data showing how the pathophysiological interactions of leucocytes and endothelial cells are modulated by the upregulation of a series of leucocyte adhesion molecules on endothelium in response to defined cytokines. ${ }^{41}$ Some of these glycoproteins can be expressed rapidly and transiently, such as GMP-140, which binds neutrophils and is translocated to the surface of endothelium in response to thrombin or histamine. ${ }^{42} 43$ In general, however, they require protein synthesis and are expressed, after a lag period, for several hours in distinct but overlapping patterns in response to different cyto- 
kines. Thus treatment of endothelium with interleukin 1, tumour necrosis factor $\alpha$, or bacterial lipopolysaccharide induces greatly augmented neutrophil adhesion, which in vitro peaks at about four to six hours and has returned to near basal levels within 24 hours. This is due, at least in part, to the induction of endothelial-leucocyte adhesion molecule 1 on endothelium, which specifically binds to an as yet unidentified neutrophil surface ligand, though adhesion mechanisms independent of this adhesion molecule are also evident. ${ }^{44} 45$ Enhancement of lymphocyte adhesion, which occurs over a longer time course (peak at 24 hours in vitro), is correlated with the increased expression of intercellular adhesion molecule 1 on endothelium, which forms a ligand pair with the leucocyte surface molecule lymphocyte function associated antigen $1 .^{46}$ More recently, pretreatment with interleukin 4 (a $T$ cell derived cytokine) was found to enhance lymphocyte adhesion to endothelium, ${ }^{47}$ and this may be related to the expression of another endothelial surface molecule, vascular cell adhesion molecule 1 , known to be a lymphocyte adhesion receptor. ${ }^{48}$

Interferon $\gamma$ uniquely increases the expression of Ia (major histocompatibility complex class II) molecules on endothelial cells, in addition to upregulating lymphocyte adhesion. ${ }^{49}$ The potential role of endothelium as an antigenpresenting cell type has been confirmed in vitro, where interferon treated endothelial cells were shown to present antigen specifically to sensitised lymphocytes and to induce lymphocyte proliferation with a comparable efficiency to macrophages. ${ }^{50}$ Endothelial cells may do this by lymphokine (interferon $\gamma$ or interleukin 1) stimulation of endothelial interleukin 6 production, ${ }^{51}$ which in turn stimulates lymphocyte interleukin 2 production to drive proliferation. Smooth muscle cells also secrete interleukin 6, however, in response to lymphokines, and present Ia antigens, but are poor stimulators of lymphocyte proliferation. Recently, an endothelial cell-specific mechanism, requiring cell contact with lymphocytes to induce proliferation, was described. ${ }^{52}$

\section{Endothelial cell pathology in scleroderma} ALTERED VASCULAR TONE AND PERMEABILITY One of the most consistent features of scleroderma is the pre-existence of Raynaud's phenomenon, though only a minority of patients with Raynaud's phenomenon go on to develop scleroderma. The excessive vasoconstriction in response to stimuli, such as cold exposure, often followed by excessive reactive hyperaemia on rewarming, is most obvious in peripheral tissue but also occurs in visceral organs. ${ }^{53}$ Direct observation of nailfold capillaries in patients shows a characteristic set of pathological changes, which in patients with Raynaud's phenomenon can be subclassified with predictive value for the subsequent development of scleroderma. ${ }^{54}$ Capillary loops become enlarged or distended, more tortuous, and their density decreases dramatically. In addition, their permeability to tracer molecules is abnormally high and the pattern of blood flow is altered, with an average slowing of flow and increased periods of stasis. It is still not clear whether these microvascular changes are primary, coexistent with, or a consequence of, arteriolar intimal hyperplasia with fibrosis and abnormal reactivity. Several small clinical trials in the 1970 s and 1980s attempted to use vasodilator drugs, or antagonists of constrictors, to alleviate Raynaud's phenomenon, with limited success and possible indications of longer term protection. For example, based on the premise that altered platelet reactivity (perhaps a consequence of endothelial damage) may lead to increased serotonin secretion, antagonists such as ketanserin were used. ${ }^{55}$ Similarly, a small study with the dilator prostaglandin $\mathrm{E}_{1}$ reported improved capillary blood flow and increased transcapillary pressure in patients with scleroderma. ${ }^{56}$

More recently, after a reappraisal of earlier histological evidence, Claman ${ }^{57}$ included mast cells in a synthesis of potential factors in the pathogenesis of scleroderma. In addition to possible effects of mast cell products on fibroblast growth and collagen synthesis, he suggested that histamine released from mast cells would contribute to the leakiness of microvessels in scleroderma. Mast cells have been implicated in neo-angiogenesis, ${ }^{58}$ and there is evidence of excess endothelial replication in scleroderma lesions, ${ }^{59}$ which, as new vessels are generally more permeable, might also contribute to the tendency to oedema.

In the light of the likely importance of basal and agonist stimulated release of endothelium derived relaxing factor (nitric oxide) for the control of blood pressure and flow it is reasonable to speculate that a failure of this mechanism is involved in the microvascular pathology of scleroderma. Although I am not aware of studies that have considered directly whether endothelium dependent vasodilator responses are selectively impaired in patients with scleroderma, this hypothesis is consistent with the observations that diseased vessels relax to endothelium independent dilators. In addition, in the absence of endothelium derived relaxing factor production several endothelium dependent vasodilators - for example, serotonin, ATP, acetylcholine-cause direct vasoconstriction and have been implicated in the generation of vessel spasm in atherosclerosis. ${ }^{60}$ Furthermore, the changes in capillary morphology in scleroderma might be a consequence of arteriolar dysfunction, leading to altered flow patterns. ${ }^{20}$

\section{EVIDENCE OF ENDOTHELIAL CELL DYSFUNCTION} OR DAMAGE

The indirect lines of evidence discussed above, which suggest that endothelial pathology is a major feature of scleroderma, are strengthened by considering other data relating to circulating markers of endothelial cell function. First noted by Kahaleh $e a^{61}$ and subsequently confirmed by others, ${ }^{6263}$ plasma concentrations of von Willebrand factor are significantly raised in a proportion (though not all) of patients with scleroderma. Raised von Willebrand factor is found in a variety of conditions where endothe- 
lial cell injury is likely, particularly in autoimmune vasculitides and systemic lupus erythematosus. ${ }^{62}$ In contrast, release of tissue plasminogen activator activity has been reported to be deficient in patients with Raynaud's phenomenon and scleroderma. ${ }^{64}$ These reciprocal changes, which alter endothelial cell properties in a prothrombotic or procoagulant direction, are elicited in vitro by treatment of endothelial cells with cytokines such as interleukin 1 and tumour necrosis factor, ${ }^{31} 65$ which also induce procoagulant tissue factor activity on endothelial cells in vitro, ${ }^{66}$ in addition to their effects (noted above) on expression of leucocyte adhesion molecules. A separate putative indicator of endothelial cell alteration or damage in scleroderma is the presence in a fraction of patients of autoantibodies that bind to endothelial cells in vitro. ${ }^{6768}$ These autoantibodies are distinct from the other circulating antibodies characteristic of scleroderma, but they also recognise fibroblasts.

\section{MECHANISMS OF ENDOTHELIAL DAMAGE}

The autoantibodies described above, like those found in patients with systemic lupus erythematosus, are not directly cytotoxic to human endothelial cells cultured in vitro. ${ }^{67} 6970$ In the particular case of Kawasaki disease (an autoimmune arteritis with extensive endothelial cell destruction) autoantibodies are present that are directly cytotoxic to cultured endothelium, but only when the endothelial cells have been pretreated with cytokines. ${ }^{71}$ Similar experiments with serum samples from patients with scleroderma have not been reported.

In view of the autoimmune nature of scleroderma, and the presence of mononuclear cell infiltrates in lesions, ${ }^{72}$ two groups studied cell mediated immune cytotoxicity to endothelium in vitro. ${ }^{697073}$ Both found that peripheral blood mononuclear cells could kill endothelial cells when cocultivated in the presence of serum samples from about $20 \%$ of patients with scleroderma, and that cytotoxicity was due to the immunoglobulin fraction. The mechanisms here are likely to include those described above in other in vitro studies - that is, interferon derived from the leucocytes enhances class II expression on endothelium and hence antigen presentation; the endothelial cells in turn induce lymphocyte interleukin 2 production and proliferation. Furthermore, interleukin 2 treatment specifically increases the binding of cytotoxic lymphocytes to endothelium in vitro. ${ }^{74}$ The likelihood that such events occur in vivo in scleroderma is enhanced by the evidence for increased interleukin 2 production in patients with scleroderma. ${ }^{75} 76$

Damage to endothelium by non-immune mechanisms has also been described. Kahaleh, LeRoy, and colleagues first found the direct cytotoxic effects of several scleroderma serum samples on endothelial cells in vitro and proposed that they were due to a functional failure of plasma antiproteinase activity. ${ }^{77} 78 \mathrm{~A}$ similar factor, cytotoxic to a variety of cell types, was reported by two further groups, ${ }^{79} 80$ though several others have failed to detect any cytotoxic activity. ${ }^{67-70}{ }^{81}$ Blake et al noted that cytotoxicity in disease serum samples could develop on storage and was associated with an increase in peroxidation. ${ }^{82}$ Drenk and Deicher purified a relatively low molecular mass $(\leqslant 5 \mathrm{kD})$ fraction from scleroderma serum samples that possessed the cytotoxic activity in vitro, ${ }^{63}$ and, in addition, when serially injected into rabbits led to raised plasma von Willebrand factor concentrations, capillary dilatation, and arterial and arteriolar intimal hyperplasia. These conflicting reports make it difficult to assess the significance of directly acting circulating cytotoxic factors in scleroderma. Even if the molecular nature of such a factor is defined, it remains unclear how the effects of a systemically acting toxic principle would be restricted, or directed to the sites of scleroderma lesions, unless its action were potentiated by a second factor in the local environment.

\section{Conclusions}

Scleroderma is a complex disease, with an autoimmune component that is more obviously directed towards the pathogenesis of fibrotic lesions, which may suggest that this facet of the disease process initiates further progression. In addition, scleroderma must be multifactorial as the presence of Raynaud's phenomenon is strongly predictive but not of itself sufficient to cause development of scleroderma. Nonetheless, small vessel pathology is intimately concerned with the disease process. This review is restricted to a consideration of the role of the endothelium, and has attempted to link the current knowledge of endothelial cell regulatory functions, concerned with specific aspects of vascular physiology and pathophysiology, to pathogenic mechanisms in scleroderma.

Two main areas have been identified where specific endothelial cell dysfunction may be involved. Firstly, failure of endothelial cell control may play a significant part in the abnormal regulation of vascular tone and permeability in scleroderma. Secondly, the ability of endothelial cells to take part in the initiation and development of immune cell mediated reactions in small vessels (which may additionally lead to endothelial cell damage or destruction), coupled with evidence that there is increased production of a variety of cytokines in scleroderma, make it very likely that these processes take place during the evolution of sclerotic lesions. Several circulating markers testify to significant disturbance of endothelial cell function, including the presence of antibodies to endothelial cells, though it is not clear whether these have any pathogenic role. Future studies to determine whether there are disturbances of either control of vascular tone or interactions with circulating lymphocytes attributable specifically to alterations in endothelial cell function in patients with scleroderma could lead to the adoption of new therapeutic measures in this complex and intractable disease.

\section{Note added in proof}

Several recent reports ${ }^{83} 84$ have indicated increased plasma concentrations of endothelin-1 
in patients with Raynaud's phenomenon, though it is not yet clear whether this is pathologically relevant or merely another marker of endothelial dysfunction.

1 Campbell P M, LeRoy E C. Pathogenesis of systemic  1975; 4: 351-68.

2 Petty R G, Pearson J D. Endothelium-the axis of vascular health and

92-102. $R$ F cells in the relaxation of arterial smooth muscle by acetylcholine. Nature 1980; 288: 373-6.

4 Furchgott R F. Role of endothelium in the responses of vascular smooth muscle to drugs. Annu Rev Pharmacol vascular smooth muscle to

5 Palmer R M J, Ferrige A G, Moncada S. Nitric oxide accounts for the biological activity of endothelium-derived relaxing factor. Nature 1987; 327: 524-6.

6 Palmer R M J, Ashton D S, Moncada S. Vascular endothelia cells synthesize nitric oxide from L-arginine. Nature 1988 333: $664-6$.

7 Gryglewski R J, Palmer R M J, Moncada S. Superoxide anion is involved in the breakdown of endothelium-derived vascular relaxing factor. Nature 1986; 320: 454-6.

8 Martin W, Villani G M, Jothianandan D, Furchgott R F Selective blockade of endothelium-dependent and glyceryl trinitrate-induced relaxation by hemoglobin and by methylene blue in the rabbit aorta. I Pharmacol Exp Ther 1985; 232: 708-16.

9 Martin W, Villani G M, Jothianandan D, Furchgott R F. Blockade of endothelium-dependent and glyceryl trinitrateinduced relaxation of rabbit aorta by certain ferrous hemoproteins. I Pharmacol Exp Ther 1985; 233: 679-85.

10 Fukuto J M, Wood K S, Byrns R E, Ignarro L J. N $\mathbf{N}^{\mathbf{U}}$-amino$L$-arginine: a new potent antagonist of $L$-arginine-mediated endothelium-dependent relaxation. Biochem Biophys Res Commun 1990; 168: 458-65.

11 Ignarro L J. Biological actions and properties of endotheliumderived nitric oxide formed and released from artery and vein. Circ Res 1989; 65: 1-2.

12 Föstermann U, Dudel C, Frölich J C. Endothelium-derived relaxing factor, likely to modulate the tone of resistance arteries in rabbit hindlimb in vivo. 7 Pharmacol Exp Ther 1987; 243: 1055-61.

13 Rivers R J, Web A L, Izzo N J, Peach M J, Duling B R Microcirculatory responses to exogenous endothelial-cell derived relaxing factor. Am F Physiol 1990; 258: H606-9.

14 Kelm M, Schrader J. Control of coronary vascular tone by nitric oxide. Circ Res 1990; 66: 1561-75.

15 Rees D D, Palmer R M J, Moncada S. The role of endothelium-derived nitric oxide in the regulation of blood pressure. Proc Natl Acad Sci USA 1989; 86: 3375-8.

16 Gardiner S M, Compton A M, Bennett T, Palmer R M J, Moncada $S$. Control of regional blood flow by endothelium derived nitric oxide. Hypertension 1990; 15: 486-92.

17 Griffith T M, Edwards D H, Davies R L, Harrison T J Evans $K$ T. EDRF coordinates the behaviour of vascular resistance vessels. Nature 1987; 329: 442-5.

18 Rubanyi G M, Romero J C, Vanhoutte P M. Flow-induced release of endothelium-derived relaxing factor. Am $\mathfrak{J}$ Physiol 1986; 250: H1145-9.

19 Davies P F, Olesen S P, Clapham D E, Morrel E M, Schoen F J. Endothelial communication. Hypertension 1988; 11 563-72.

20 Griffith T M, Edwards D H. Basal EDRF activity helps to keep the geometrical configuration of arterial bifurcations close to the Murray optimum. I Theor Biol 1990; 146: 545-73.

21 Yanagisawa M, Kurihara H, Kimura S, et al. A novel potent vasoconstrictor peptide produced by endothelial cells Nature 1988; 332: 411-5.

22 Lüscher T M, Richard V, Tschudi M, Yang Z, Boulanger C. Endothelial control of vascular tone in large and small arteries. F Am Coll Cardiol 1990; 15: 519-27.

23 Michel C C. Capillary permeability and how it may change. 7 Physiol (Lond) 1988; 404: 1-29.

24 Renkin E M. Capillary transport of macromolecules: pores and other endothelial pathways. $\mathcal{f}$ Appl Physiol 1985; 58 315-25

25 Majno G, Shea S M, Leventhal $M$. Endothelial contraction induced by histamine-type mediators: an electron-microscopic study. F Cell Biol 1969; 42: 647-72.

26 Williams T J, Peck M J. Role of prostaglandin-mediated vasodilatation in inflammation. Nature 1977; 270: 530-2.

27 Wedmore C V, Williams T J. Control of vascular permeability by polymorphonuclear-leukocytes in inflammation. Nature 1981; 289: 646-50.

28 Harlan J M. Leucocyte-endothelial interactions. Blood 1985; 65: $513-25$.

29 Esmon N L. Thrombomodulin. Semin Thromb Hemost 1987, 13: 454-63.

30 Van Hinsbergh V W M. Regulation of the synthesis and secretion of plasminogen activators by endothelial cells. secretion of plasminogen act
Haemostasis 1988; 18: $307-27$.

31 Schleff R R, Bevilacqua M P, Sawdey M, Gimbrone M A Loskutoff D J. Cytokine activation of vascular endothelium. Effects on tissue-type plasminogen activator and type 1 Effects on tissue-type plasminogen activator and type
plasminogen activator inhibitor. F Biol Chem 1988; 263: plasminogen
32 Handin R I, Wagner D D. Molecular and cellular biology of Von Willebrand factor. In: Coller B S, ed. Progress in hemostasis and thrombosis. Vol 9. Philadelphia: Saunders, 1989: 233-59.

33 Moncada S. Biological importance of prostacyclin. $\mathrm{Br} \mathfrak{J}$ Pharmacol 1982; 76: 3-31.

34 Radomski M W, Palmer R M J, Moncada S. The role of nitric oxide and cGMP in platelet adhesion to vascular endothe-
lium. Biochem Biophys Res Commun 1987; 148: 1482-9.

35 Staub N C, Schultz E L, Albertine K H. Leukocytes and pulmonary vascular injury. Ann NY Acad Sci 1982; 384: 332-43.

36 Streeter P R, Ronse B T N, Butcher E C. Immunohistologic and functional characterisation of a vascular addressin involved in lymphocyte homing into peripheral lymph nodes. F Cell Biol 1988; 107: 1853-62.

37 De Bono D. Endothelium-lymphocyte interactions in vitro. I Adherence of non-allergised lymphocytes. Cell Immunol 1976; 26: 77-88.

38 Lackie J M, De Bono D. Interactions of neutrophil granulocytes and endothelium in vitro. Microvasc Res 1977; 13: 107-12.

39 Yu C-L, Haskard D O, Johnson A R, Ziff M. Human interferon increases binding of $T$ lymphocytes to endothelia cells. Cell Immunol 1985; 62: 554-60.

40 Bevilacqua M P, Pober J S, Wheeler M E, Cotran R S, Gimbrone $M$ A. Interleukin-1 acts on cultured human vascular endothelium to increase the adhesion of poly morphonuclear leukocytes, monocytes and related leukocytic cells lines. F Clin Invest 1985; 76: 2003-11.

41 Pober J S, Cotran R S. Cytokines and endothelial cell biology. Physiol Rev 1990; 70: 427-51

42 Geng J-G, Bevilacqua M P, Moore K L, et al. Rapid GMP-140. Nature 1990; 343: 757-60.

43 Toothill V J, Van Mourik J A, Niewenhuis H K, Metzelaa $M$ J, Pearson J D. Characterisation of the enhanced adhesion of neutrophil leukocytes to thrombin-stimulated endothelial cells. F Immunol 1990; 145: 283-91.

44 Bevilacqua M P, Pober I S, Mendrick D L, Cotran R S Gimbrone $M$ A. Identification of an inducible endothelialleukryte adhesion molecule Proc Natl Acad Sci USA 1986; 83: 4533-7.

45 Dobrina A, Schwartz B R, Carlos T M, Ochs H D, Beatty P G, Harlan J M. CD11/18-independent neutrophil adherence to inducible endothelial-leucocyte adhesion molecules in vitro. Immunology 1989; 67: 502-8.

46 Dustin M L, Springer T A. Lymphocyte function-associated antigen-1 (LFA-1) interaction with intercellular adhesion molecule-1 (ICAM-1) is one of at least three mechanisms for lymphocyte adhesion to cultured endothelial cells. f Cell Biol 1988; 107: 321-31.

47 Thornhill M H, Kyan-Aung V, Haskard D O. IL-4 increase human endothelial cell adhesiveness for $\mathrm{T}$ cells but not for neutrophils. F Immunol 1990; 144: 3060-5.

48 Onutrophils. F Immunol 1990, 144: 3060 . cloning of vascular cell adhesion molecule 1 , a cytokine induced endothelial protein that binds to lymphocytes. Cell 1989; 59: 1203-11.

49 Pober J S, Collins T, Gimbrone M A, et al. Lymphocyte recognise human vascular endothelial and dermal fibroblas a antigens induced by recombinant interferon. Nature 1983; 305: 726-9.

50 Wagner C R, Vetto R M, Burger D R. The mechanism of antigen presentation by endothelial cells. Immunobiolog 1984; 168: 453-69.

51 Jirik I R, Podor T J, Hirano T, et al. Bacterial LPS and inflammatory mediators augment IL- 6 secretion by human endothelial cells. $\mathcal{F}$ Immunol 1989; 142: 144-7.

52 Hughes C C, Savage C O, Pober J S. Endothelial cells augment $T$ cell interleukin 2 production by a contactdependent mechanism involving CD2/LFA-3 interaction. dependent mechanism involving

53 Fahey P J, Utell M J, Condemi J J, Green R, Hyde R W. Raynaud's phenomenon of the lung. Am $\mathcal{F}$ Med 1984 76: 263-9.

54 Carpentier P H, Maricq H R. Microvasculature in systemic sclerosis. Rheum Dis Clin North Am 1990; 16: 75-91.

55 Longstaff J, Gush R, Williams E H, Jayson M I. Effects of ketanserin on peripheral blood flow, haemorheology and platelet function in patients with Raynaud's phenomenon. f Cardiovasc Pharmacol 1985; 7 (suppl 7): S99-101.

56 Martin M F R, Tooke J E. Effects of prostaglandin $E_{1}$ on microvascular haemodynamics in progressive systemic sclerosis. $B M F$ 1982; 285: 1688-90.

57 Claman H N. On scleroderma. Mast cells, endothelial cells and fibroblasts. FAMA 1989; 262: 1206-9.

58 Folkman J. How is blood vessel growth regulated in normal and neoplastic tissue? Cancer Res 1986; 46: 467-73.

59 Kazandjian S, Feissinger J-N, Camilleri J P, Dadonne J P Housset $E$. Endothelial cell renewal in skin of patients with progressive systemic sclerosis: an in vitro autoradiographic study. Acta Derm Venereol (Stockh) 1982; 62: 425-9.

60 Ludmer P L, Selwyn A P, Shook T L, et al. Paradoxical vasoconstriction induced by acetylcholine in atherosclerotic coronary arteries. $N$ Engl $f$ Med 1986; 315: 1046-51.

61 Kahaleh M B, Osborn I, LeRoy E C. Increased factor VIII/von Willebrand factor antigen and von Willebrand factor activity in scleroderma and Raynaud's phenomenon. Ann Intern Med 1981; 94: 482-4.

62 Gordon J L, Pottinger B E, Woo P, Rosenbaum J, Black C $M$. Plasma von Willebrand factor in connective tissue disease. Ann Rheum Dis 1987; 46: 491-2.

63 Drenk F, Deicher H R G. Pathophysiological effects of 
endothelial cytotoxic activity derived from sera of patients with progressive systemic sclerosis. $\mathcal{F}$ Rheumatol 1988; 15 with proger 74 .

64 Holland C D, Keegan A L, Wood K, et al. The fibrinolytic response to DDAVP in systemic sclerosis and controls. Progress in Fibrinolysis. 1983; 6: 107-10.

65 Nawroth P P, Stern D M. Modulation of endothelial cell hemostatic properties by tumor necrosis factor. 7 Exp Med 1986; 163: 740-5

66 Bevilacqua M P, Pober J S, Majeau G, Cotran R S, Gimbrone $M$ A Interleukin 1 induces biosynthesis and cell surface expression of procoagulant activity in human vascular endothelial cells. F Exp Med 1984; 160: 618-21.

67 Rosenbaum J R, Pottinger B E, Woo P, Black C M, Byron $M$ A, Pearson J S. Measurement and characterisation of circulating anti-endothelial cell IgG in connective tissue diseases. Clin Exp Immunol 1988; 72: 450-6.

68 Hashemi S, Smith C D, Izaguirre C A. Anti-endothelial cell antibodies: detection and characterisation using a cellular enzyme-linked immunosorbent assay. $\mathcal{f} \mathrm{Lab}$ Clin $\mathrm{Med}$ 1987; 109: 434-40.

69 Penning C A, Cunningham J, French M A H, Harrison G, Rowell N R, Hughes P. Antibody-dependent cytotoxicity of human vascular endothelium in systemic sclerosis. Clin Exp Immunol 1984; 57: 548-56.

70 Marks R M, Czerniecki M, Andrews B S, Penny P. The effects of scleroderma serum on human microvascular endothelial cells. Induction of antibody-dependent cellular cytotoxicity. Arthritis Rheum 1988; 31: 1524-34.

71 Leung D Y M, Geha R F, Newburger J W, et al. Two monokines, interleukin 1 and tumor necrosis factor, render monokines, interleukin 1 and tumor necrosis factor, render cultured vascular endothelial cells susceptible to lysis by antibodies circulating during Kawasaki syndrome. F Exp
Med 1986; 164: 1958-72.

72 Fleischmajer R, Perlish J S, Reeves J R T. Cellular infiltrates in scleroderma skin. Arthritis Rheum 1977; 20: 975-84.

73 Holt C M, Lindsey N, Moult J, et al. Antibody-dependent cellular cytotoxicity of vascular endothelium. Characterization and pathogenic associations in systemic sclerosis. Clin Exp Immunol 1989; 78: 359-65.
74 Aronson $F$, Libby $P$, Brandon E $P$, Janicka $M W$, Mier J W. IL-2 rapidly induces natural killer cell adhesion to human endothelial cells. A potential mechanism for endothelial injury. F Immunol 1988; 141: 158-63.

75 Umehara H, Kumagai S, Ishida H, Suginoshita T, Maeda M, Imura $\mathrm{H}$. Enhanced production of interleukin 2 in patients with progressive systemic sclerosis. Arthritis Rheum 1988; 31: 401-7.

76 Kahaleh M B, LeRoy E C. Interleukin-2 in scleroderma: correlation of serum level with extent of skin involvement and disease duration. Ann Intern Med 1989; 110: 446-50.

77 Kahaleh M B, Sherer G K, LeRoy E C. Endothelial injury in scleroderma. 7 Exp Med 1979; 149: 1326-35.

78 Kahaleh M B, LeRoy E C. Endothelial injury in scleroderma. A protease mechanism. f Clin Invest 1983; 101: 553-60.

79 Cohen S, Johnson A R, Hurd E. Cytotoxicity of sera from patients with scleroderma: effects on human endothelial cells and fibroblasts in culture. Arthritis Rheum 1983; 26: $170-8$.

80 Meyer D, Haim T, Dryll A, Lansaman J, Ryckewaert A. Vascular endothelial cell injury in progressive systemic sclerosis and other connective tissue disease. Clin Exp Rhermatol 1983; 1: 29-34.

81 Summers G D, Weiss J B, Jayson M I V. Failure of sera from patients with scleroderma to exhibit cytotoxicity towards human umbilical vein endothelial cells. Rheumatol Int 1984; 5: 9-13.

82 Blake D R, Winyard P, Scott D G I, Brailsford S, Blann A, Lunec J. Endothelial cell cytotoxicity in inflammatory
vascular diseases - the possible role of oxidised lipoproteins. Ann Rheum Dis 1985; 44: 176-82.

83 Yamane K, Kashiwagi H, Suzuki N, et al. Elevated plasma levels of endothelin-1 in systemic sclerosis. Arthritis Rheum 1991; 34: 243-4.

84 Zamora M R, O'Brien R F, Rutherford R B, Weil J V. Serum endothelin-1 concentrations and cold provocation in primary Raynaud's phenomenon. Lancet 1990; 336: 